\title{
Anolis equestris (Cuban Giant Anole). Distribution.
}

Date of observation: 26 August 2013. Location: Lorient, Saint-Barthélemy. Coordinates: 17.905417, -62.822692. Voucher: image. Following a call from a resident, an adult male Cuban Giant Anole was captured in the area of Lorient on the island of Saint-Barthélemy. The lizard was on a Noni Tree (Morinda citrifolia), and according the residents it pursued a juvenile Lesser Antillean Iguana. Found near a tree nursery, it probably arrived on the island hidden in plants from Florida, as have Cuban Treefrogs (Osteopilus septentrionalis) and Red Corn Snakes (Pantherophis guttatus). This is the first record of this species on the Island of Saint-Barthélemy.

David Lédée, davidledeesbh@gmail.com and Karl Questel, La Réserve Naturelle de Saint-Barthélemy, BP 683 Gustavia, 97099 Saint-Barthélemy Cedex, sciencenaturestbarth@ gmail.com.

Citation: Lédée D, Questel K. 2013. Anolis equestris (Cuban Giant Anole). Distribution. Caribbean Herpetology 42:1.

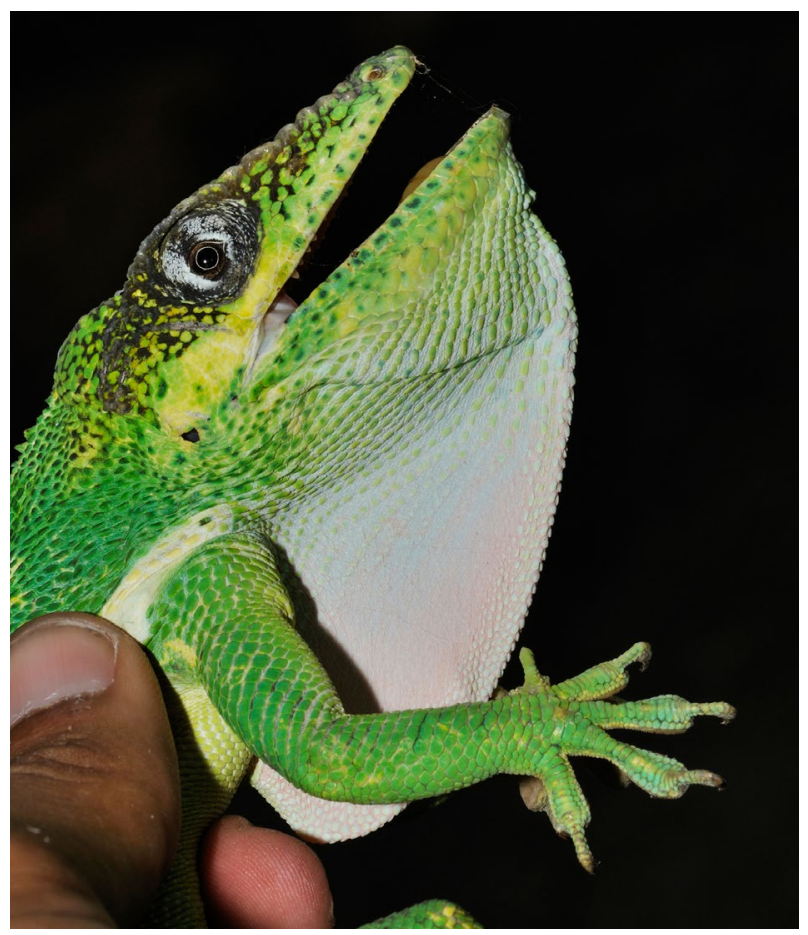

Published online 1 September 2013 